\title{
Los gráficos y la pandemia. Reflexiones para la educación científica en tiempos de incertidumbre
}

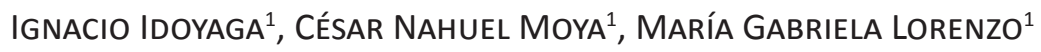

${ }^{1}$ Universidad de Buenos Aires. Facultad de Farmacia y Bioquímica. Centro de Investigación y Apoyo a la Educación Científica. Ciudad Autónoma de Buenos Aires, Argentina.

iidoyaga@ffyb.uba.ar

Recibido 1ㅇde julio 2020 - Aceptado 16 de noviembre 2020

\section{Resumen}

La pandemia por COVID-19 pone en evidencia que ciertos saberes y modos de conocer vinculados a la educación científica no alcanzan al común denominador de la ciudadanía. En particular, este trabajo centra su atención en la proliferación de diferentes maneras de estructurar el discurso propias del circuito comunicativo de las ciencias, en los medios de comunicación y en los anuncios oficiales de los dirigentes políticos. En este sentido, la utilización de diversos tipos de representaciones gráficas para comunicar en la pandemia invita a una pormenorizada reflexión en base a resultados de investigación sobre el rol de los gráficos en la educación científica, el interés del profesorado y las posibilidades de los estudiantes. Así, se logran plantear perspectivas para una educación post pandémica que incluya lo representacional en la formación científica de la ciudadanía.

Palabras clave: Representaciones gráficas, educación científica para la ciudadanía, COVID-19.

\begin{abstract}
The COVID-19 pandemic shows that certain knowledge and ways of knowing linked to science education do not reach the common denominator of citizenship. In particular, this work focuses on the use of different types of graphical representations during the pandemic in mass media communication and political discourse. This invites a detailed reflection based on our research results on the role of graphics in science education. Thus, it is possible to raise perspectives for a post-pandemic education that includes the representational issue in science education for citizenship.
\end{abstract}

Keywords: graphical representations, science education for citizenship, COVID-19. 


\section{La educación científica en época de pandemia}

La pandemia de COVID-19, cuya denominación proviene de los vocablos latinos corona y virus y del término disease (enfermedad en inglés), que irrumpió a fines de 2019 (de ahí el número 19), nos interpela y obliga a la reflexión de toda la sociedad. La salud pública, la economía, las ciencias políticas, entre otros campos del saber, son puestas en jaque al tiempo que el colectivo de las ciencias biomédicas redobla esfuerzos para crear nuevo conocimiento sobre la situación sanitaria y rápidamente transferirlos en tecnología para intervenir la realidad. Nuevos modos de relación se imponen en el cotidiano de los aglomerados urbanos e, incluso, en zonas rurales, en todo el mundo. La educación, los sistemas educativos y las prácticas docentes no son esquivas al vertiginoso cambio que imponen la enfermedad y los esfuerzos para contenerla. Es por esto que, quienes cultivamos las didácticas específicas y, en particular, la didáctica de las ciencias naturales, debemos superar rápidamente la actitud contemplativa y aceptar, como otras ciencias sociales, el desafío de analizar estas nuevas configuraciones para poder intervenir de manera fundamentada en los procesos de gestión de la información científica por parte de los ciudadanos y sus gobernantes.

La educación enfrenta múltiples desafíos en el contexto actual. La imposibilidad de reunirnos exige recurrir a nuevos modos, plataformas y estrategias para que estudiantes y profesores podamos construir conocimientos compartidos. La escuela y toda institución educativa enfrentan tensiones organizativas en tanto buscan garantizar el cumplimiento de su rol social. El predominio de dispositivos escolares presenciales y propios de la modernidad, la escasez de prácticas que incluyan tecnologías y la desigualdad que registran nuestros países en América Latina con respecto al acceso a recursos digitales y al desarrollo de competencias para usarlos, complejizan la tarea de profesores e instituciones frente a la demanda de continuidad de las clases en tiempos de distanciamiento social. Además, se hacen visibles las necesidades de actualización y perfeccionamiento docente, que exceden por mucho el uso de programas o recursos informáticos, y se centran en las discusiones didácticas sobre cómo enseñar con este tipo de mediación.

Una revisión rápida de la cobertura periodística de la crisis y de la respuesta de la población en redes sociales o en medios tradicionales nos permite evidenciar que ciertos saberes y modos de conocer vinculados a la educación científica no alcanzan al común denominador de la ciudadanía. Incluso, varios comunicadores sociales parecen no poder explicitar cuestiones básicas que deberían haber sido enseñadas y, presumiblemente, aprendidas en la educación obligatoria. Esta situación, que aporta incertidumbre y ansiedad a la ya dolorosa realidad, pone de manifiesto la necesaria e incompleta tarea de educar en ciencias para la ciudadanía (Macedo, 2016). Es decir, en el contexto de crisis sanitaria y cambio permanente, podemos vislumbrar claramente la educación científica no sólo como derecho individual, sino también como estrategia colectiva para enfrentar problemas de corte socio científicos. Más aún, la apropiación de las ideas de las ciencias es, al mismo tiempo, de gran valor cultural para los individuos y de vital importancia para las sociedades contemporáneas.

Las dificultades que detectamos en relación con los discursos circulantes en medios masivos de comunicación y redes sociales son numerosas y diversas. Sin ánimos de realizar un detalle exhaustivo y pormenorizado de los problemas en relación al uso de los modelos científicos, podemos comentar algunas situaciones que se repiten con frecuencia y que ponen en juego terminología propia de las ciencias naturales, alcanzando cierto grado de credibilidad en una audiencia que no se ha apropiado acabadamente de esos modelos.

En primer lugar, son notables las referencias al SARSCoV-2 (denominación del agente viral vinculado a la enfermedad COVID-19, según el Comité Internacional de Taxonomía de Virus, ICTV por su acrónimo en inglés) como un organismo vivo, desconociendo su carácter de parásito intracelular obligado y, en consecuencia, ocultando la ocurrencia de un ciclo viral de duración determinada. Esto desdibuja la comprensión de los periodos de latencia y dificulta el cumplimiento de recomendaciones sanitarias. También, guarda vínculos con la práctica de la automedicación y la falta de reporte ante síntomas. Además, complica el cumplimiento de las recomendaciones sanitarias con respecto a la inactivación del virus en superficies (desinfección) y la adherencia comunitaria a las medidas de prevención dispuestas.

En segundo lugar, aparece la confusión entre vacunación, como medida de prevención, y tratamiento específico de la enfermedad. Esto toma un matiz especial en medio de la proliferación de movimientos antivacuna registrada en los últimos años. Así, cuestiones como la inmunidad adquirida por la comunidad y la autolimitación de una epidemia están lejos de explicitarse. Estas cuestiones podrían no estar declaradas en la mayoría de los diseños curriculares de la educación obligatoria. Sin embargo, los modos de conocer que estos documentos deberían promover, en caso de 
contemplar la formación para la ciudadanía, como la obtención empírica de datos y su tratamiento estadístico, facilitarían la comprensión de estas ideas.

En tercer lugar, se encuentran desdibujadas las distinciones entre ciencia, salud y tecnología, intercambiando roles indistintamente entre quienes están abocados a estudiar la estructura molecular del virus, quienes intentan desarrollar una vacuna o testean fármacos y quienes diagnostican y tratan a los pacientes enfermos. Otro aspecto que suma a la confusión es la proliferación de documentos propios de la ciencia de frontera, como resultados preliminares de estudios, de gran valor al interior de la comunidad científica. El tratamiento de estos preprints como si fueran productos definitivos conduce a que, en poco tiempo, la población reciba información cambiante y, a veces, contradictoria. En este contexto, una educación que incluya aspectos de la naturaleza de las disciplinas científicas (Adúriz-Bravo, 2020), del funcionamiento del sistema científico, del quehacer de sus actores y que encare esfuerzos para transparentar las complejas relaciones entre ciencia, tecnología y sociedad (Martín-Páez, Aguilera, Perales-Palacios y Vílchez-González, 2019), se vislumbra como de interés público e importancia estratégica. Esto obedece a la necesidad de la ciudadanía de analizar críticamente los discursos de los comunicadores y realizar una validación de los mismos en pos de posicionarse políticamente.

Por último, queremos centrar nuestra atención en la proliferación de diferentes maneras de estructurar el discurso propias del circuito comunicativo de las ciencias, en los medios y en las comunicaciones oficiales de los dirigentes políticos. Estos usos comunicativos son incorporados con la finalidad de validar las decisiones sanitarias y las medidas de emergencia. Es decir, el híbrido semiótico que sostiene la comunicación en ciencias (Lemke, 2002) irrumpe y domina la comunicación social en tiempos de la pandemia. Esto se hace evidente cuando la prensa escrita o el periodismo en distintas plataformas recurren, reiteradamente, al uso de representaciones gráficas y expresiones algebraicas que actúan de manera sinérgica con la lengua natural (Lombardi, Caballero y Moreira, 2009) y que deben ser procesadas (Pozo, 2017) en pos de construir sentido sobre la evolución de la crisis sanitaria.

En esta crisis podemos notar de forma transparente como el soporte semiótico, el juego de diferentes registros representacionales que sustenta la construcción y el tratamiento de conocimiento científico, cumple diversas funciones. De manera habitual, al interior del sistema científico, las representaciones tienen fun- ciones retóricas (García García, 2005) que permiten el armado de las ideas de las ciencias y operan como agentes de mediación (Roth y McGinn, 1997) en la discusión entre los actores del sistema. Pero, cuando estas representaciones son usadas por comunicadores y dirigentes cumplen otras funciones. Así, como ya señalamos, representaciones no tan habituales en medios de comunicación, como un sinnúmero de representaciones gráficas propias de la academia y, particularmente, gráficos cartesianos construidos empíricamente desde las ciencias biomédicas, comienzan a ser moneda corriente. En estos casos, procesos de explicitación sucesivos de modelos o ideas (Pozo, 2001) vinculados a estas representaciones permiten compartir significados con la población al tiempo que son presentados como evidencia y argumento de posiciones y decisiones en salud, en economía y en todo otro aspecto de la vida pública.

En esta revisión centraremos nuestro interés en el papel de los gráficos, particularmente cartesianos y mayoritariamente producidos en el seno de la comunidad de las ciencias biomédicas, en situaciones que se vinculan con la toma de decisiones políticas y las formas de comunicarlas y legitimarlas. Esta decisión, que guía nuestro análisis, obedece a dos cuestiones: la abundancia del uso de este tipo particular de representación durante la crisis y las dificultades para construir significados a partir de gráficos. A estas últimas las hemos identificado en más 15 años de investigación en el tema, evidenciando una deuda en la educación científica (Idoyaga y Lorenzo, 2019). En los próximos apartados, desarrollaremos pormenorizadamente estas cuestiones, brindaremos algunos ejemplos emblemáticos, revisaremos nuestros principales resultados de investigación sobre gráficos y propondremos algunos caminos para repensar la educación científica para la ciudadanía en la nueva realidad de la post-pandemia.

\section{Los gráficos en la comunicación durante la crisis}

Las representaciones gráficas abundan en la comunicación vinculada a la pandemia, siendo utilizadas de modo sinóptico, formando una unidad indivisible, con el discurso en la lengua natural (Perales y Jiménez, 2002). Entre la gran variedad de representaciones encontramos, en primer término, mapas de la cantidad de casos (figura 1a), de la distribución de las cepas del virus (figura 1b) o de cómo la enfermedad se disemina a lo largo y ancho del planeta (figura 1c). Incluso, se diseñaron aplicaciones web o para dispositivos móviles que permiten acceder a estos mapas que se van actualizando en tiempo real (https://who.maps.arcgis.com/). 


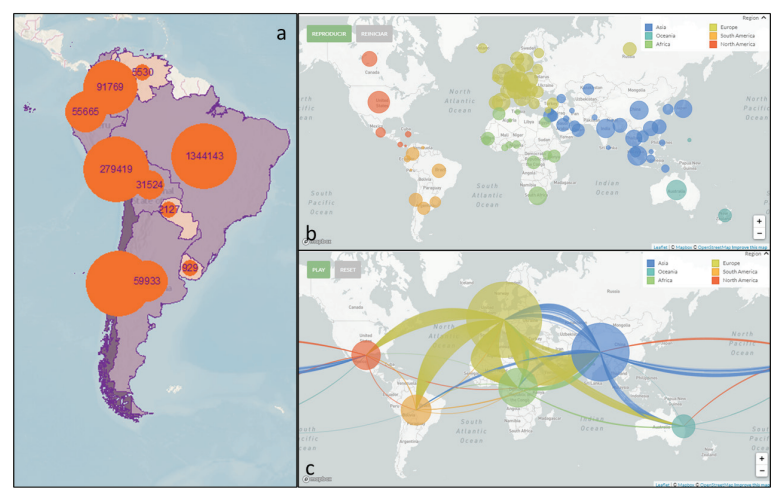

Figura 1. Ejemplos de diversos mapas sobre coronavirus; a: mapa de cantidad de casos (fuente: OMS); b: mapa de la distribución de las cepas del virus (fuente: nextstrain.org); c: mapa de la diseminación mundial de las cepas del virus (fuente: nextstrain.org)

En segundo término, aparecen diagramas que representan la filogenia del virus, muy propios de la biología (figura 2).

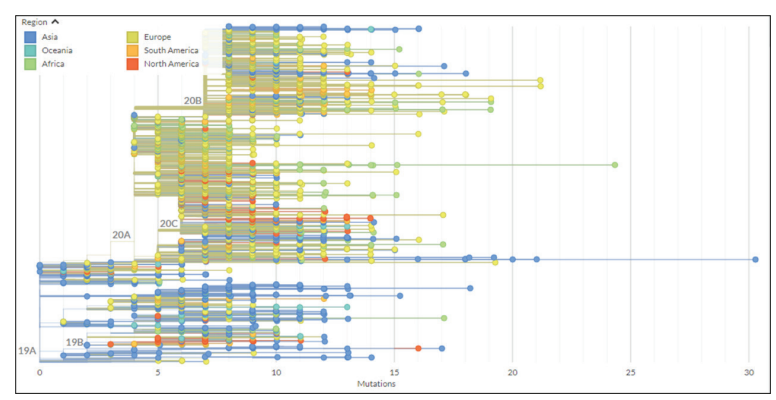

Figura 2. Diagrama filogenético del virus (fuente: nextstrain. org)

En tercer término, proliferan las ilustraciones del virus (figura 3a) y las infografías sobre las medidas de prevención (figura 3b).

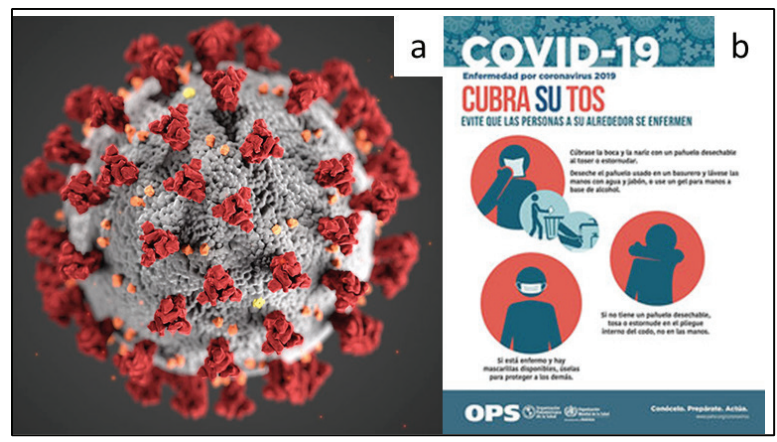

Figura 3. a: ilustración del virus (fuente: cdc.gov); b: infografía sobre las medidas de prevención (fuente: OPS).
Por último, los gráficos, particularmente los cartesianos, que dan cuenta de la evolución de los casos (figura 4a), del estado del sistema sanitario (figura 4b), de las fases de la enfermedad (figura 4c) y de la aparición de anticuerpos (figura 4d) se diseminan por todas las pantallas y medios.

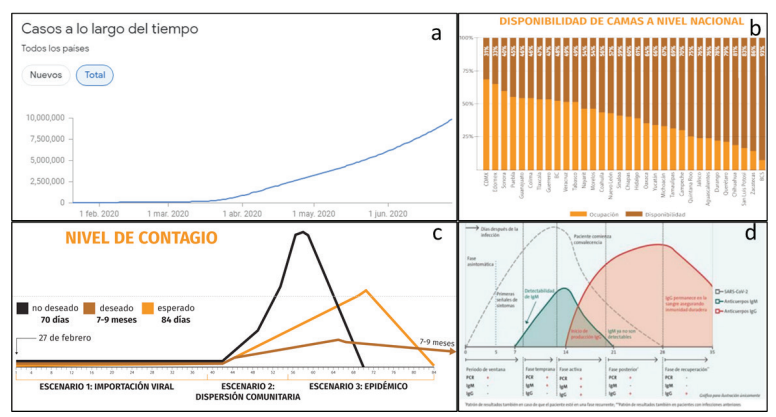

Figura 4. Ejemplos de diversos gráficos relacionados a la pandemia de covid-19; a: evolución de los casos a lo largo del tiempo (fuente: wikipedia.org); b: disponibilidad de camas en hospitales (fuente: infobae.com); c: fases de contagio de la enfermedad (fuente: infobae.com); d: aparición de anticuerpos en relación con la evolución de la enfermedad (fuente: camaragranada.org).

Muchas de estas representaciones son propias de las ciencias biomédicas y se las utiliza como evidencia en pos de legitimar discursos políticos. Sin embargo, es menester mencionar que la posibilidad de cada sujeto para construir significado a partir de cada una de estas representaciones requiere del despliegue de una serie de actividades cognitivas ligadas a la semiosis (Duval, 2017). Estas actividades son específicas y no surgen espontáneamente, por lo que deberían enseñarse en la educación obligatoria para promover el aprendizaje con y a partir de las representaciones gráficas.

Los gráficos, como tipo particular de representación gráfica, resultan un caso paradigmático, no sólo por su abundancia en el universo de representaciones puesto en juego, sino más bien por su relevancia en los discursos políticos de primera línea. Más aún, algunas expresiones que podemos considerar écfrasis, es decir representaciones verbales de representaciones visuales, se construyen a partir de gráficos. Es decir, pueden considerarse representaciones en el registro de llegada (lengua natural), que se originan a través de una actividad de conversión (Duval, 2017) a partir de otro registro semiótico (el gráfico).

A continuación, presentaremos el caso de dos jefes de gobierno y/o estado que recurren al uso sinóptico de gráficos de las ciencias biomédicas y realizan conversiones para justificar posiciones políticas bien diferen- 
tes entre sí. En el primer caso nos referimos a las intervenciones públicas de Boris Johnson, primer ministro del Reino Unido, quien luego padecería COVID-19, y, en segundo lugar, al presidente de la Nación Argentina, Alberto Fernández.

En primer lugar, podemos recordar las intervenciones públicas de Boris Johnson. En su anuncio del 12 de marzo de 2020 (Figura 5), escoltado por Chris Witty, director médico del gobierno, y Patrick Vallance, asesor científico en jefe, sentenció: "tenemos que aplastar el sombrero" ("squash the sombrero"). Esta declaración, mezcla de écfrasis y metáfora, que generó gran polémica en todo el mundo, hace referencia a la necesidad de disminuir la velocidad de los contagios, es decir, lo que gráficamente puede entenderse como la pendiente de la recta tangente en un punto determinado de la curva en la representación del número total de casos en función del tiempo, generalmente medido en días. Esto, es lo que muchos otros dirigentes llaman aplanar la curva y está vinculado a necesidad de no superar la capacidad de respuesta de los sistemas sanitarios.

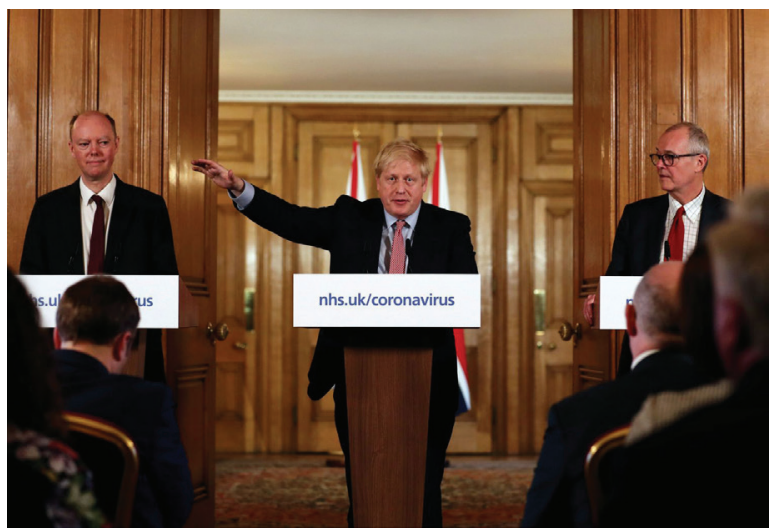

Figura 5. Boris Johnson, junto a los doctores Chris Witty y Patrick Vallance, realizando un gesto que hace referencia al acto de aplastar un sombrero. (fuente: elpais.com).

El diario El país de España, en su edición digital del 13 de marzo de 2020, describió la intervención del primer ministro de la siguiente manera:

El tiempo demostrará si la metáfora utilizada por Boris Johnson para explicar su estrategia contra el coronavirus es una genialidad o una temeraria bufonada. 'Tenemos que aplastar el sombrero' ("squash the sombrero"), dijo el primer ministro en su comparecencia del jueves. Se refería al gráfico que su máximo asesor científico, Patrick Vallance, había mostrado previamente con los cálculos de la evolución de la epidemia en el Reino Unido. En el peor de los casos, la curva ascendente y descendente adquiría un per- fil cónico y superaba con creces la capacidad de respuesta del Servicio Nacional de Salud (NHS, en sus siglas en inglés). Con el escenario perseguido por el Gobierno, la evolución se asemejaba más al sombrero de un gánster que al de un charro mexicano (de Miguel, 2020).

En un principio, Johnson y su equipo recurrieron a los gráficos cartesianos y al híbrido comunicativo propio de las ciencias naturales para justificar el gradualismo de las acciones sanitarias en pos de preservar la economía, al tiempo que se desarrollaba la ansiada inmunidad comunitaria. La política del gobierno británico dio un abrupto giro a los pocos días y la justificación de las nuevas medidas recurrió no sólo al mismo tipo de comunicación sino también a las mismas representaciones, a los mismos gráficos, proponiendo ahora un procesamiento conceptual diferente (Postigo y Pozo, 2000).

En segundo lugar, podemos considerar las declaraciones de Alberto Fernández, presidente de la Nación Argentina, quien llevó adelante muy tempranamente y por Decreto de Necesidad y Urgencia múltiples medidas sanitarias, entre las que se destaca el Aislamiento Social Preventivo y Obligatorio (ASPO). El 10 de abril de 2020, Fernández, acompañado por sus ministros y asesores, se dirigió a la población a través de la cadena nacional de radio y televisión.

Esta intervención resulta de particular interés para nuestro análisis, ya que recurrió de manera reiterativa y redundante al uso de gráficos. El presidente se puso de pie al lado de una pantalla y compartió una abundante cantidad de slides donde podían verse distintos gráficos cartesianos propios de las ciencias biomédicas (Figura 6).Prácticamente, toda la intervención del primer magistrado tuvo que ver con explicitar su procesamiento de estas representaciones a fin de validar y justificar el rumbo de sus políticas.

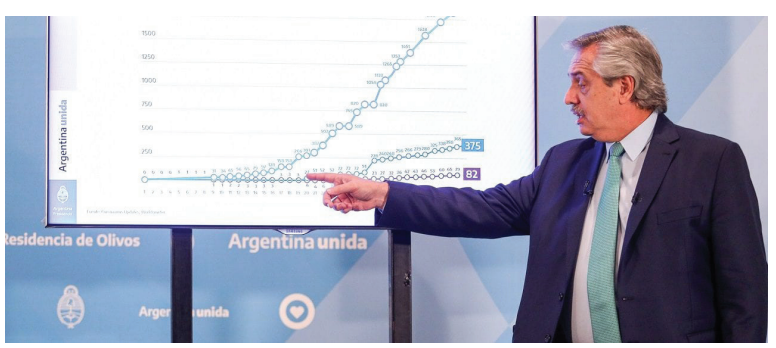

Figura 6. Alberto Fernández justificando las medidas sanitarias a partir de un gráfico cartesiano por la cadena nación de radio y televisión. 
Más allá de los casos presentados y sin ánimo de entrar en ninguna polémica sobre la pertinencia de las diferentes formas de encarar la crisis, nos queda claro que los gráficos se perciben como recursos valiosos en la comunicación y para la fundamentación de las políticas públicas relacionadas con la pandemia.

En este escenario, la ciudadanía se enfrenta al desafío de construir significado a partir de estas representaciones. Esta construcción debería ser crítica y reflexiva, de modo de promover la validación de los discursos políticos y así contribuir al posicionamiento frente a las acciones y a la adhesión a las medidas de salud pública. Es por esto que, teniendo como premisa que las representaciones y los modelos de la ciencia que representan son indisociables y constituyen contenidos propios de la educación científica, nos proponemos reflexionar sobre cómo se abordan estas cuestiones en la educación obligatoria y superior y que impacto tienen en la formación de sujetos críticos que deben desempeñarse en las democracias contemporáneas.

\section{Los gráficos en la educación científica}

La crisis que enfrentamos y, en particular, las características de la comunicación orquestada suman razones para sostener que en la educación obligatoria debe llevarse adelante un proceso de alfabetización gráfica que permita a la ciudadanía la revisión crítica y la validación de los discursos. Esta alfabetización, al igual que la literaria y la matemática, permite que los estudiantes hagan propias las reglas y restricciones de un sistema representacional de vital importancia en la vida pública, en la sociedad y en la cultura, incluyendo las disciplinas científicas. Si bien, el proceso al que hacemos referencia tiene lugar en diferentes áreas disciplinares, la educación científica resulta un espacio privilegiado toda vez que los gráficos son representaciones propias de su circuito comunicativo y elementos indisociables de los modelos científicos. Es decir, una educación científica para la ciudadanía debería incluir, como ya se mencionó, la enseñanza programática de los registros semióticos que sustentan e integran sus modelos. Más aún, la apropiación de estos modelos no es independiente de la aprehensión de los sistemas de representaciones.

La necesaria revisión sobre el lugar que ocupan los gráficos en la educación en ciencias y tecnología puede partir de la revisión de varios referentes teóricos y de diversos resultados de investigación, algunos propios. En este sentido, incluso en las ideas de Kant y Descartes podemos encontrar la cuestión de la representa- ción como eje de la discusión educativa. Esto hace necesario que para proseguir con nuestra reflexión contemos con una definición operativa de esta idea. La noción de representación ha aparecido varias veces a lo largo de los años con diferentes significados e implicancias. A los fines de este trabajo, podemos entender las representaciones como constructos de los sujetos que refieren a objetos, fenómenos, conceptos o ideas (García García, 2005) que reúnen las características y atributos de sus referentes valorados como esenciales según el tipo y la finalidad de la representación (Pérez Echeverría, Martí y Pozo, 2010).

Desde una perspectiva didáctica, es posible reconocer dos grandes tipos de representaciones: las internas y las externas (Duval, 1999) o privadas y públicas (Cox, 1999). Las primeras son constructos mentales, de carácter idiosincrático y privado. Las segundas se constituyen a partir de complejos sistemas de signos, poseen materialidad, son públicas y pueden tomar significados diferentes para el sujeto que las utiliza. Por ejemplo, la lengua natural, el álgebra y las representaciones gráficas. Es importante destacar que existe una relación dialógica (Lorenzo y Pozo, 2010) entre ambos tipos de representaciones. Es decir, las representaciones externas no son una mera copia de las internas, ya que los procesos de explicitación (Pozo, 2017) permiten transformar las representaciones mentales existentes y generar nuevas.

En la educación científica y en otros discursos, como los que abundan durante la pandemia, el circuito comunicativo se articula en torno al uso de diferentes registros semióticos, distintos sistemas de representaciones externas. Recurrir a diferentes modos semióticos es una necesidad que impone la naturaleza misma del objeto que se pretende representar, ya que cada tipo de representación facilita abordar de una manera particular el objeto en cuestión (Lemke, 1993). Entonces, podemos afirmar que los diferentes modos semióticos actúan de manera sinérgica, contribuyendo a la construcción de un significado canónico (Lemke, 1997; Roth, Bowen y McGinn, 1999). En este sentido, las representaciones gráficas, el álgebra y la lengua no son simplemente un complemento el uno del otro, sino que, el significado de uno puede ser modificado por el otro y viceversa, dando un nuevo resultado que es fruto de la interacción de los lenguajes (Márquez y Prat, 2005). De esto modo, la multiplicidad representaciones de diferente naturaleza semiótica sobre un mismo objeto no resulta redundante, en el sentido de que constituyan formas equivalentes de expresar las mismas ideas, sino que, por el contrario, conducen a 
interpretaciones conjuntas de las cuales se obtiene un nuevo significado.

Las representaciones gráficas (Lieben y Downs, 1992), también llamadas pictóricas (Eysenk y Keane, 1990), descriptivas (Schnotz y Bannert, 2003), incrustaciones (Roth et al., 1999), imágenes visuales (Otero, 2004), gráfico-visuales (Lemke, 1998) o no-textuales (Lombardi et al., 2009), son un constituyente fundamental del híbrido semiótico (Lemke, 2002) que se despliega en la comunicación en ciencia, tecnología y salud. Podemos entender estas representaciones como el tipo particular de representación externa compuesto por diferentes elementos (puntos, líneas, manchas) que se disponen sobre una superficie bidimensional y, utilizando como recurso semiótico sus características espaciales, se combinan para encriptar significados.

Las representaciones gráficas pueden clasificarse respondiendo a diferentes criterios. Existe una gran cantidad y variedad de propuestas de clasificación, las cuales pueden resultar más o menos pertinentes según el contexto particular y los propósitos con los que se utilicen. En el marco de este trabajo, consideraremos una clasificación centrada en la clase y forma en que es presentada la información, así como en la relación que esa información tiene con el objeto o fenómeno representado (Pozo y Postigo, 1999). De este modo, pueden distinguirse cuatro tipos de representaciones gráficas: diagramas, gráficos, ilustraciones y mapas. Los diagramas representan espacialmente relaciones conceptuales, los gráficos relaciones cuantitativas entre variables, los mapas relaciones espaciales y las ilustraciones relaciones de carácter reproductivo.

Los gráficos, como ya comentamos, son el tipo de representación gráfica que reviste de mayor interés para esta reflexión ya que cobran especial relevancia en la comunicación política y mediática en relación a la crisis sanitaria por COVID-19. Son representaciones de alto grado de abstracción (Shah, Freeman y Vekiri, 2005) que poseen elementos sintácticos, semánticos y estructurales, muchos de ellos implícitos y no evidentes. Su principal virtud es la de transformar una información cuantitativa en otra más fácilmente comprensible, aunque también pueden inducir a errores cuando carecen de elementos informativos suficientes (Shah y Hoeffner, 2002).

Existen distintos tipos de gráficos: pictogramas, cartogramas, circulares o por sectores y cartesianos, entre otros. La posibilidad que brindan todos estos tipos de gráficos a la hora de representar en el espacio relaciones cuantitativas entre variables los tornan de suma importancia en el discurso de las ciencias naturales y en su enseñanza (Jiménez Tejada, Sánchez-Monsalve y González-García, 2013; Arias, Leal y Organista, 2011). En particular, los gráficos cartesianos constituyen una parte medular del circuito comunicativo en ciencias y del trabajo experimental. Es decir, están en el corazón del trabajo científico, fundamentalmente porque brindan al mismo tiempo la posibilidad de representar la experiencia del trabajo con datos empíricos y sostener estilizados modelos científicos. Esta posibilidad dual los convierte en recursos valiosos en la discusión sobre salud en general, y en la comunicación sobre la pandemia, en particular. Es por todo esto que los gráficos cartesianos nos resultan particularmente interesantes a la hora de pensar la educación científica desde la coyuntura actual.

\section{La interpretación de los gráficos}

Los gráficos, como cualquier otro registro semiótico, pueden ser entendidos como representaciones al identificar los cuatro elementos que son necesarios para la construcción de significados. Así, en toda representación externa podemos reconocer la existencia de un objeto o fenómeno representado (material o ideal), un sistema de signos, las reglas de representación que conectan esos signos con el referente y un proceso cognitivo que implique el uso de la representación. Este último componente resulta determinante ya que no existe representación si no existe un proceso mental que permita relacionar entre sí los componentes anteriores.

Los estudiantes de ciencias ponen en juego complejos procesos cognitivos cuando deben procesar la información contenida en los gráficos en pos de construir conocimientos que excedan a la propia representación. De igual manera, como se observa al analizar la comunicación en la pandemia, la ciudadanía debe procesar la información de los gráficos en pos de construir conocimientos que le permita tomar decisiones y posiciones. Este procesamiento requiere no solo conocer los sistemas de signos y las reglas de representación sino, más que nada, apropiarse de la actividad cognitiva ligada a la semiosis que permite recuperar el significado de la representación.

La construcción de significados a partir de gráficos implica el procesamiento de su información a tres niveles (Postigo y Pozo, 2000): a nivel de la información explícita, implícita y conceptual. El procesamiento a nivel de la información explícita está relacionado con el reconocimiento de los elementos presentes en el gráfico, por 
ejemplo: el título, las unidades, la escala y los valores de las variables, entre otros. Se trata de realizar una lectura local del gráfico. En cambio, el procesamiento a nivel de la información implícita exige que el gráfico sea interpretado globalmente, supone un cierto conocimiento del sistema semiótico y requiere encontrar patrones y tendencias, identificando relaciones entre las variables involucradas. Por ejemplo, la determinación de la pendiente de una recta corresponde a este nivel. Finalmente, el procesamiento a nivel de la información conceptual requiere en gran medida de los niveles anteriores y está centrado en el establecimiento de relaciones a partir del análisis global de la estructura del gráfico. Esto hace necesario ir más allá de la información contenida de modo explícito e implícito en el gráfico y recuperar otros conocimientos disponibles en la memoria a largo plazo para realizar interpretaciones, explicaciones o predicciones sobre el fenómeno representado en el gráfico.

Nuestra línea de trabajo nos permite entender este último nivel como una instancia de reconstrucción intrínseca de la representación para resignificarla, por lo que demanda una estrecha relación entre los conocimientos conceptuales y el sistema representacional. Los elementos del contenido conceptual se funden con los del sistema de tal manera que el lector deja de percibir las tendencias de los gráficos para entenderlas como relaciones significativas entre variables. Es la forma en la que los expertos construyen e interpretan gráficos para fines y contextos determinados.

Estos tres niveles de procesamiento que comentamos pueden presentarse de manera no lineal, incluso podrían no ser procesos totalmente independientes uno de otro. No es posible la comprensión conceptual de un gráfico sin cierto conocimiento del código y la sintaxis, pero el aprendizaje de estos aspectos está vinculado a los contenidos que le confieren significado a la representación. Además, es posible que se logren identificar tendencias en un contexto determinado y no en otro. Los elementos conceptuales no aparecen exclusivamente en la última etapa, sino que necesariamente dan sentido a elementos más explícitos o estructurales del sistema, aunque la fusión entre concepto y representación sí está restringida a este nivel (Idoyaga y Lorenzo, 2016).

La posibilidad de procesar gráficos a nivel explícito e implícito suele alcanzarse en la escolaridad obligatoria (Núñez, Banet Hernández y Cordón Aranda, 2009). Sin embargo, varias investigaciones han puesto de manifiesto que tanto los estudiantes universitarios como los sujetos titulados en ciencias presentan di- ficultades para acceder a la información gráfica más allá de los dos primeros niveles (Leinhardt, Zalanvsky y Stein, 1999; García García y Perales, 2006; Pozo y Flores, 2015) e interpretarla (Font, Acevedo, Castells y Bolite, 2008), así como para construir representaciones (Álvarez Tamayo, 2011; Solar, Deulofeu y Azcárate, 2015). La imposibilidad de acceder a la información conceptual podría ser una de las causas de los frecuentes problemas que manifiestan los estudiantes para el aprendizaje de las ciencias naturales (Suárez y Cordero, 2008; Galagovsky, Di Giacomo y Castelo, 2009; Chamizo, 2010; Matus, Benarroch y Nappa, 2011). Más aún, en la coyuntura actual, esta imposibilidad representa un claro obstáculo para el ejercicio pleno de la ciudadanía, ya que varias personas podrían estar impedidas de comprender, más allá de un modo superficial, los discursos sobre la pandemia que recurren a gráficos y, consecuentemente, no podrían validarlos o posicionarse al respecto.

Nuestros estudios, que se inscriben en el área de la didáctica de las ciencias naturales y de la salud, muestran claramente que, si bien la mayoría de los estudiantes universitarios suelen alcanzar los dos primeros niveles de procesamiento sin problema, el procesamiento a nivel de la información conceptual resulta de difícil acceso. Para ilustrar esta situación comentaremos a continuación las características generales y los principales resultados de un estudio realizado entre los años 2014 y 2017 con la participación de 269 estudiantes universitarios de ciencias de la salud del ámbito de la Ciudad de Buenos Aires.

En el mencionado estudio abordamos aspectos relacionados con la construcción de conocimiento científico mediada por gráficos. Para esto, indagamos las conceptualizaciones de los estudiantes sobre este tipo particular de representación, que modelan sus esquemas mentales durante el aprendizaje, y el tipo de procesamiento que realizan cuando trabajan con gráficos en las clases. Además, buscamos conocer si el contenido representado tenía algún tipo de influencia en el procesamiento de la información de los gráficos. Para lograr todo esto, implementamos una metodología de enfoque mixto, de carácter cuali cuantitativo, que combinó una investigación de campo, particularmente encuestas, con cuasiexperimentos, basados en tareas especialmente diseñadas.

En primer lugar, con respecto a las conceptualizaciones de los estudiantes, la investigación nos permitió reconocer la percepción de los gráficos como herramientas propias del ámbito universitario, de poca importancia en ejercicio de la ciudadanía. Además, el carácter re- 
presentacional de los gráficos y sus potencialidades cognitivas aparecieron subestimados. Esta concepción pragmática indicaría que los estudiantes tienen dificultades para comprender el rol de las representaciones en el híbrido discursivo de la disciplina y para reconocer instancias de aprendizaje a partir de estas.

En segundo lugar, con respecto al procesamiento de los gráficos, los resultados evidenciaron que los niveles de la información explícita e implícita parecen alcanzarse fácilmente. En cambio, el procesamiento a nivel de la información conceptual resulta dificultoso para la mayoría de los participantes y es sensible al contenido representado. Es decir, el procesamiento conceptual, que siempre requiere de los niveles anteriores, se verá afectado por lo representado, ya que el número y la naturaleza de las representaciones internas a movilizar para realizar este procesamiento depende fuertemente de aquello a lo que hace referencia el gráfico. Si pensamos en el número de representaciones internas a movilizar en el caso de gráficos sobre la pandemia, podemos reconocer cómo esta dificultad se verá exacerbada. Basta repasar la gran cantidad y complejidad de las ideas de las ciencias naturales y de la salud que hay que poner en tensión con las representaciones puestas en juego durante la crisis sanitaria para procesarlas. Solo por mencionar algunas: concepto de virus, ciclo viral, contagio, inmunidad individual y comunitaria, capacidad del sistema sanitario, tratamiento y tasa de mortalidad.

En relación a lo anterior, este estudio refuerza una idea que ya comentamos. Las representaciones, en su pleno uso, no son solo el código, el soporte, las reglas y restricciones, sino que también encierran y engloban los procesos cognitivos que permiten descifrarlos. Por ende, los gráficos no son la simple envoltura de los contenidos representados, la forma de presentarlos. La estructura de la representación y el contenido representado dialogan entre sí y con el sujeto que los procesa, haciendo que este procesamiento no sea el mismo en términos de demanda y posibilidades, según cual fuese el contenido representado a pesar de que muchos de los gráficos sean estructuralmente equivalentes. Más aún, en la coyuntura actual, deberíamos tener presenta la posibilidad de considerar también los factores no cognitivos, emocionales, que junto con las conceptualizaciones estarían condicionando las posibilidades cognitivas.

Por último, puede proponerse una vinculación entre las conceptualizaciones de los estudiantes y las dificultades identificadas para acceder al procesamiento a nivel de la información conceptual. Esta vinculación encuentra sustento en la idea que realizar actividades cognitivas y, especialmente, aprender a partir de gráficos, implica necesariamente procesarlos conceptualmente. Es decir, internalizarlos y ponerlos en tensión con representaciones internas, que, durante este proceso, son rediseñadas, redefinidas o reconstruidas, pudiendo posteriormente exteriorizarse en diferentes registros. Esto último requiere, además, el reconocimiento del carácter representacional por parte de los estudiantes, ya que la construcción de significado implica reconocer aquello que no cambia entre las distintas representaciones, originales o nuevas, internas o externas, aquello que se mantiene constante.

\section{La enseñanza de los gráficos}

Aprender a leer, a escribir, a sumar o a utilizar un mapa requiere la ayuda de otras personas más competentes en esas tareas. Lo mismo sucede con la construcción e interpretación de gráficos. Sin esta ayuda directa, la cual es asumida en gran medida por la escolarización, la apropiación de estos sistemas externos de representación no sería posible (Martí, 2003). Sin embargo, no debemos olvidar que, como se evidencia en la coyuntura de la crisis por COVID-19, en los contextos informales también se construyen valores, conocimientos y actitudes que impactan en el proceso de aprehensión de los gráficos.

Es oportuno remarcar que el proceso de adquisición al que hacemos referencia requiere de contextos educativos formales y actividades planificadas por el profesorado. Esto obedece, en parte, a las particularidades de los gráficos como representaciones externas (registros permanentes e independientes de su creador) que hacen que su interpretación suponga la reconstrucción de la intención de la persona que los creó (Martí, 2003). Estos sistemas y la cantidad de información que vinculan a través de sus propiedades formales hacen necesaria una enseñanza específica y reglada. Esto se contrapone a la idea popular que una imagen (un gráfico) vale más que mil palabras. De hecho, estas representaciones lejos están de ser autoevidentes, por lo que su enseñanza no puede limitarse exclusivamente a presentarlas o incorporarlas en los discursos.

La enseñanza de los gráficos, y particularmente, de los gráficos cartesianos, se desarrolla en distintos espacios curriculares a lo largo de la educación obligatoria. No obstante, las prácticas que se proponen en las clases de ciencias en relación a los gráficos cartesianos, en su mayoría, sólo incluyen la ubicación de pares ordenados. Así, los estudiantes no trabajan con las interac- 
ciones entre las variables ni con la relación de la representación con los contenidos representados. Más aún, en una aproximación didáctica tradicional el gráfico es el punto final de la instrucción y, si bien se incluyen cuestiones vinculadas a la construcción de los mismos, no se trabajan la interpretación ni la utilización de los gráficos como herramientas para resolver problemas (Ainley, Nadi y Pratt, 2000).

Queda claro que las decisiones acerca del enfoque general, las sutilezas de la aplicación, el diseño, la secuenciación y la planificación de las actividades dependen fuertemente del profesorado. Así, resultan determinantes sus conocimientos, creencias y conceptualizaciones sobre los gráficos como tipo particular de representación externa, como elemento central del híbrido comunicacional de las disciplinas científicas, como herramienta epistémica y, fundamentalmente, como objeto de una enseñanza específica en cursos de ciencias. Esta fuerte y compleja dependencia es lo que nos inclina a utilizar, para estructurar la reflexión, un modelo que permita hacer foco en el profesor como gerente de la enseñanza de y con gráficos.

El programa de investigación denominado Conocimiento Didáctico del Contenido (CDC) presenta un modelo que permite centrar la atención sobre los profesores (Farré, Idoyaga y Lorenzo, 2014; Lorenzo, Farré y Rossi, 2018).El CDC puede entenderse como el conocimiento que va más allá del contenido disciplinar per se y que llega a la dimensión del conocimiento del contenido para la enseñanza (Shulman,1986, 1987). Es un conocimiento característico e idiosincrásico de los profesores, que surge de la relación entre el conocimiento disciplinar y el didáctico. Específicamente, para este análisis podríamos postular un $\mathrm{CDC}$ referido a los gráficos, o directamente Conocimiento Didáctico de los Gráficos (CDG), entendiendo a estas representaciones como un contenido propio en los cursos de ciencias (Idoyaga y Lorenzo, 2013).

Como parte de su CDG, los profesores deben conocer tanto las fortalezas y limitaciones de sus alumnos cuando construyen e interpretan gráficos, incluyendo sus concepciones alternativas más comunes, así como también la mejor forma de organizar, secuenciar y evaluar el uso de estas representaciones para lograr aprendizajes significativos (Barnett y Hodson, 2001). Es decir, este conocimiento permite al profesorado diagramar la enseñanza de las actividades cognitivas ligadas a la semiosis que se realizan en el registro de los gráficos y que son vitales, como deja clara la coyuntura de la pandemia, para el desempeño de la ciudadanía.
Existen al menos tres actividades cognitivas vinculadas a los gráficos que deben enseñarse: la formación, el tratamiento y la conversión (Duval, 1999, 2017). Las actividades de formación implican la generación de una nueva representación en un registro semiótico preexistente a través de la aplicación de las reglas de conformidad, aquellas que codifican y limitan el registro. Se trata de construir nuevos gráficos. Las actividades de tratamiento o de expansión informacional buscan ampliar la información de la representación en el mismo registro, por ejemplo, el trazo de una recta tangente $u$ otras operatorias que se realizan sobre los gráficos. Por último, las actividades de conversión suponen un cambio de registro. Por ejemplo, pasar de un gráfico a la lengua natural y al álgebra o viceversa.

Las actividades de conversión son las más complejas, dada la laxitud de sus reglas, y las menos enseñadas en la educación obligatoria. Esto obedece al fenómeno de encapsulamiento representacional vinculado a la economía de tratamiento. Es decir, sólo se convierten representaciones cuando el registro de llegada ofrece mejores posibilidades de tratamiento. Sin embargo, quienes bregamos por la enseñanza multirepresentacional (Treagust, 2018) consideramos esta actividad como especialmente interesante, ya que puede constituir una evidencia de aprendizaje. En otras palabras, reconocer las invariancias de las distintas representaciones convertidas y poder sostenerlas da cuenta de la internalización de los atributos esenciales del referente (Duval, 1999).

Las cuestiones vinculadas a la enseñanza de los gráficos guardan relación con las posibilidades de los estudiantes para interpretar y construir estas representaciones. En este sentido, analizar la enseñanza en contextos formales permite comprender, en parte, como la educación científica aporta a la formación ciudadana. Específicamente, en lo que respecta a la apropiación de estos sistemas semióticos, que la situación sanitaria actual revela como necesarios para la vida plena en las sociedades contemporáneas, donde los modos de comunicar de la ciencia y la tecnología cobran particular relevancia. Por ende, con el fin de aportar insumos a la reflexión, comentaremos las características generales y los principales resultados de un estudio que llevamos adelante entre los años 2013 y 2014 con la participación de 19 profesores universitarios de primeros cursos de ciencias naturales del ámbito de la Ciudad de Buenos Aires.

El estudio que realizamos buscó reconocer el rol de los gráficos en la enseñanza de las ciencias, la forma en que los profesores conceptualizan este tipo par- 
ticular de representación gráfica, sus estrategias de enseñanza y el posible impacto de sus prácticas en el aprendizaje de sus estudiantes. A tal fin, analizamos las conceptualizaciones de los profesores y tratamos de describir los aspectos generales de su CDG. Para lograr todo esto, se planteó una investigación de campo, con entrevistas y observación de clases, que responde a un enfoque cualitativo y cuya finalidad es fundamentalmente descriptiva.

En primer lugar, nuestros resultados mostraron que los profesores piensan en los gráficos como herramientas para la práctica docente o el trabajo académico. Así, se los entiende, fundamentalmente, como instrumentos con funciones retóricas. En contraposición, se registró una escasa consideración del carácter representacional, de los límites, restricciones y funciones de las representaciones y de las potencialidades cognitivas de estas. Todo esto no permitiría que se planteen escenarios educativos propicios para la construcción de significados canónicos de las ideas científicas cuando se recurre a gráficos, lo que se torna necesario para el ejercicio de la ciudadanía en múltiples situaciones sociales, como la que estamos atravesando.

En segundo lugar, encontramos que, en sus clases, los profesores presentan los gráficos como facilitadores del acceso a la información proveniente de la data, es decir, como organizadores de datos empíricos. En todas las clases observadas son escasas las actividades tendientes a que los estudiantes construyan conocimientos a partir de estas representaciones. En particular, los aspectos vinculados a la interpretación y a la construcción de conocimiento a partir de representaciones aparecen poco considerados. El tiempo dedicado al análisis de gráficos estuvo centrado, en todos los casos, en consideraciones sobre el cálculo de la pendiente de la función. No se observaron cuestiones referidas al carácter semiótico de las representaciones ni ninguna actividad o reflexión que marque la relación entre la representación y los conceptos.

En relación a lo anterior, también evidenciamos que los tópicos relacionados al análisis de gráficos se trataron de manera independiente y mostraron escasas vinculaciones con el resto de los temas abordados. Si bien una primera aproximación podría invitar a pensar que esta separación responde a la idea de que las habilidades puestas en juego para construir e interpretar gráficos son diferentes, el poco tiempo dedicado al análisis sugiere una subestimación de las últimas, que podría tener que ver con el supuesto de autoevidencia de las representaciones que opera en el profesorado (López-Manjón y Postigo, 2016).
En base a ambos resultados, es posible postular cierta identidad entre la conceptualización pragmática de los gráficos, la idea de autoevidencia y el énfasis sobre la construcción de estas representaciones. Es decir, la consideración pragmática y la idea de autoevidencia limitan las prácticas en clase a la correcta construcción de estas representaciones. En cambio, si se toma conciencia del complejo sistema de signos y reglas que permiten, no solo la construcción de nuevas representaciones (formación), sino que a la vez restringen su uso (tratamiento) y, además, son vitales para el cambio de registro (conversión) que evidencia la construcción de significado, se propondrían otro tipo de actividades. Estas últimas, deberían tender a que los estudiantes hagan uso de los gráficos para aprender sobre y con estos y no solo como punto final de sus tareas.

La situación descripta en los párrafos anteriores nos permite pensar que no todos los contextos de la educación formal resultan favorables para la aprehensión de las habilidades cognitivas requeridas para encontrar el significado profundo de los gráficos, lo que es necesario para posicionarse socialmente ante los discursos que incluyen este tipo de representaciones. Por un lado, el desarrollo de las habilidades que permiten el procesamiento de las representaciones, necesario para alcanzar el significado canónico de las ideas de la ciencia y de otros campos disciplinares, es difícil de lograr en ausencia de actividades que pongan en relieve las potencialidades cognitivas de éstas. Por otro lado, el escaso reconocimiento del carácter semiótico de las representaciones podría dificultar la apropiación de las reglas que conectan los signos con las ideas que constituyen el conocimiento científico. Por lo tanto, es necesario prestar especial atención a los aspectos representacionales en la educación obligatoria, en general, y en la educación científica, en particular, ya que estos resultan fundamentales en la formación de la ciudadanía.

\section{Los gráficos en los materiales didácticos}

La comprensión de los gráficos como contenidos de la educación científica implica que, también, los estudiemos como elementos incluidos en los libros de texto y otros materiales didácticos que se manejan en la enseñanza. Así, resulta llamativo que aproximadamente la mitad de la superficie impresa de los libros de ciencias corresponde a algún tipo de representación gráfica (Perales y Jiménez, 2002; López-Manjón y Postigo, 2016). Además, es notable la abundancia de estas representaciones en otros materiales, tales como las presentaciones que se proyectan en clase, guías de trabajos prácticos y/o problemas y exámenes. 
Todos estos materiales incluyen una gran variedad y cantidad de representaciones gráficas $y$, en muchos de ellos, predominan los gráficos cartesianos (Idoyaga, Maeyoshimoto, Moya y Granchetti, 2017). Un gráfico puede incluirse en los materiales con tres propósitos básicos (Garcia Garcia, 2015): exponer una idea o concepto (uso didáctico expositivo), plantear una pregunta o problema (uso didáctico problémico) o en el marco de una propuesta de actividad experimental o de campo (uso didáctico instrumental). Es más, una misma representación es plausible de ser incluida con propósitos diferentes, pudiendo ser usada para promover el desarrollo de distintas actividades cognitivas ligadas a la semiosis.

En esta línea de trabajo, varios investigadores encontraron que el uso de los gráficos en estos materiales suele emplearse casi exclusivamente para la descripción de principios y fenómenos (García García, 2005). O sea, los gráficos incluidos no se presentan como instrumentos de explicación y predicción vinculados a los procesos de producción del conocimiento científico o la validación de los discursos que los incluyen. Esto último, como fuimos comentando reiteradamente, hace a la formación para la ciudadanía y se torna evidentemente necesario en el contexto de la pandemia.

Otros aspectos a considerar sobre los gráficos incluidos en los materiales didácticos de ciencias naturales guardan relación con el origen del referente y la cantidad de información. En primer término, podemos distinguir entre los gráficos que dan cuenta del proceso de recolección de datos y se construyen desde la empírea como los que abundan en la comunicación asociada a la crisis por COVID-19 (uso científico experimental) y los que presentan estilizados modelos científicos (uso científico teórico). La figura 7 presenta un gráfico de uso científico experimental y la Figura 8 uno de uso científico teórico, ambos relacionados con la situación sanitaria. En segundo término, la cantidad de información de estas representaciones no siempre es la misma. Así, puede cuantificarse la información que se incluye dentro del gráfico (información intrínseca) y la que está en su contexto de inserción íntimamente vinculada a este (información extrínseca).

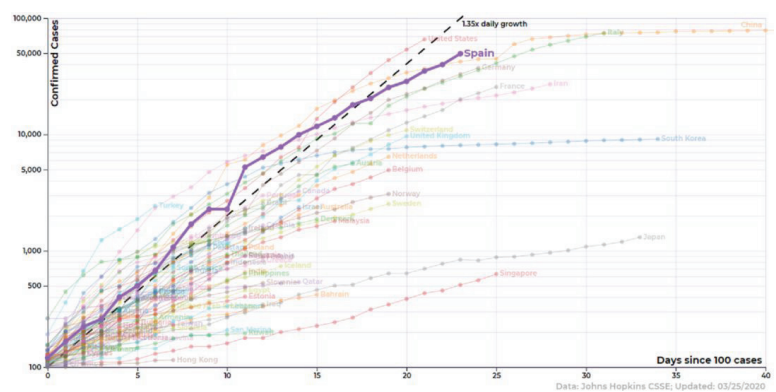

Figura 7. Gráfico de uso científico experimental: evolución del virus en distintos países. (Fuente: cadenaser.com).

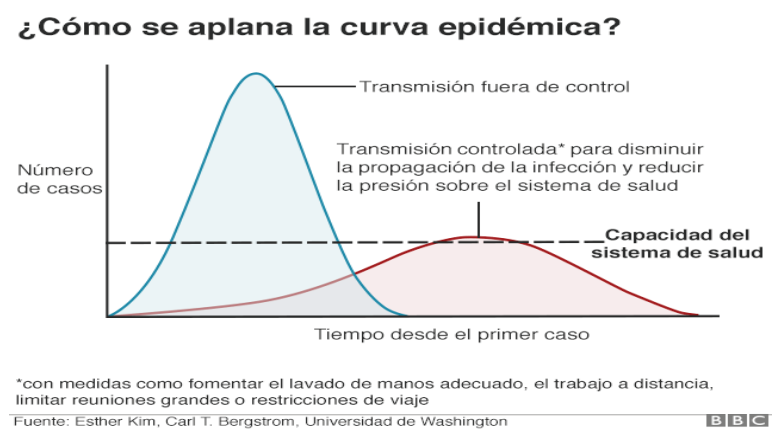

Figura 8. Gráfico de uso científico teórico: evolución del número de caso. (Fuente bbc.com).

El conocimiento de los usos y de la naturaleza de los gráficos que se incluyen en estos materiales nos resulta particularmente interesante, ya que entendemos que este análisis permite completar una descripción más acabada del entorno de enseñanza y aprendizaje que condiciona la aprehensión de todo sistema de representación. Por ende, y a modo de ejemplo, comentaremos las características generales y los principales resultados de un estudio que realizamos en el año 2016 y que implicó el análisis de materiales didácticos usados en un primer curso de física universitaria: un libro de texto, 42 guías, 7 presentaciones y un compendio de 100 preguntas de examen.

El estudio que realizamos buscó reconocer distintos aspectos de las representaciones gráficas presentes en los materiales didácticos analizados. En particular, estudiamos el tipo de representaciones gráficas incluidas, los usos didácticos y científicos y la cantidad de información intrínseca y extrínseca de los gráficos. Para lograr todo esto, se planteó una investigación documental, con enfoque mixto, fundamentalmente descriptiva, que incluyó el diseño de una guía de observación especialmente diseñada.

En primer lugar, en todos los materiales relevados los gráficos evidenciaron ser el tipo de representación grá- 
fica más abundante, lo que da cuenta de su centralidad en el discurso de las ciencias. En particular, considerando la finalidad de los materiales, se podría pensar que los gráficos son reconocidos como elementos propios de la educación en la física. Por otra parte, también se podría pensar que la abundancia de este tipo particular de representación gráfica responde al fenómeno de encapsulamiento representacional, ya comentado. Más aún, en algunos capítulos disciplinares el recuento de gráficos se ve especialmente exacerbado. Esto, podría inducir a pensar que estas representaciones son propias del desarrollo y la comunicación de determinadas ideas y no naturalmente ubicuas, como se evidencia en los medios de comunicación durante la emergencia sanitaria.

En segundo lugar, con excepción del compendio de preguntas de examen, en todos los materiales estudiados predominaron los gráficos de uso didáctico expositivo. Esto podría representar un obstáculo para que los estudiantes comprendan a estas representaciones como herramientas cognitivas útiles para resolver problemas y realizar predicciones y como elementos indisociables de la práctica experimental. Adicionalmente, el uso científico teórico fue mayoritario. Esto, sumado a lo anterior, podría llevar a entender a este tipo particular de representación como un elemento propio de la retórica de la disciplina, desdibujando el carácter empírico de esta última. Es decir, como un elemento que pertenece al campo de lo teórico o modélico, como un producto terminado y ausente en el quehacer del experimentador.

Finalmente, la cantidad de información intrínseca y extrínseca que presentaron todos los gráficos estudiados fue relativamente baja (Idoyaga y Lorenzo, 2018). En particular, se registró que los gráficos con usos didácticos problémico e instrumental y uso científico experimental portaban mayor cantidad de información que los de uso didáctico expositivo y uso científico teórico. Estos dos aspectos podrían contribuir al entendimiento distorsionado de los gráficos (incluyendo su contexto de inserción) como elementos poco informativos, que siempre deberían estar acompañados por otras fuentes de información.

\section{Perspectivas para la educación representacional en la postpandemia}

Este trabajo da cuenta de nuestra reflexión sobre algunos aspectos de la educación científica para la ciudadanía que se tornan de sumo interés en el contexto de la emergencia sanitaria por COVID-19. En particular, destacamos la necesidad de que la enseñanza formal promueva aprendizajes que permitan el uso y la valoración de las representaciones gráficas, particularmente los gráficos, como prótesis de la mente, que permiten potenciar nuestras posibilidades cognitivas (Pozo, 2017). Es decir, como instrumentos semióticos que posibiliten no solo la comunicación, sino, también, la construcción de conocimientos científicos. Asimismo, presentamos evidencia empírica que revela que dichos aprendizajes no se alcanzan satisfactoriamente durante la educación obligatoria, e incluso en los primeros años de carreras vinculadas a las ciencias biomédicas.

En el primer apartado planteamos la necesidad de llevar adelante una reflexión sobre la educación durante la pandemia nutrida por la didáctica de las ciencias naturales. Identificamos algunos de los principales desafíos de distintos actores de la educación formal y describimos diversas problemáticas vinculadas al uso de modelos de las ciencias naturales y de la salud en los medios masivos de comunicación.

En el segundo apartado dejamos claro como el híbrido semiótico de las ciencias naturales, que es central en su comunicación y en la construcción de conocimiento científico, se despliega en los discursos políticos y mediáticos. Además, describimos dos casos paradigmáticos en los que primeros mandatarios de democracias modernas justifican acciones disímiles recurriendo al uso de gráficos.

En el tercer apartado compartimos una propuesta teórica que permite comprender la centralidad de los gráficos, como tipo particular de representación gráfica, en la construcción de conocimiento en las comunidades científicas, en el trabajo experimental propio de las disciplinas naturales y de la salud y en la educación en ciencia y tecnología.

En el cuarto, quinto y sexto apartados revisamos aspectos vinculados al aprendizaje y a la enseñanza de los gráficos en contextos formales, incluyendo el análisis de materiales didácticos. En todos los casos, compartimos las características generales y los principales resultados de investigaciones propias que representan un significativo aporte a la comprensión de lo que ocurre cuando profesores y estudiantes recurren a gráficos para construir significados compartidos. Abordamos, entre otras cuestiones, el procesamiento de estas representaciones, el conocimiento de los profesores que modela su enseñanza y los usos de las mismas en los materiales didácticos.

Todo lo anterior lo hicimos fundamentalmente para disparar la reflexión sobre estos sistemas externos de 
representación como elementos de primario protagonismo en la comunicación vinculada a la emergencia sanitaria y para remarcar que la apropiación de sus reglas y restricciones es fundamental para el ejercicio de la ciudadanía. Son múltiples y diversos los ejemplos que podríamos seguir revisando en el contexto actual para reforzar esta tesis.

En este sentido, podemos preguntarnos, por ejemplo, en qué medida la ciudadanía comprende cabalmente que un achatamiento de la curva no significa un menor número de casos totales, sino una distribución diferente de los mismos en el tiempo y que implicaría la necesidad de extender las medidas de aislamiento. Esto, en el gráfico puede conectarse con persistencia de valor del área bajo la curva. Podríamos, también, cuestionarnos sobre el entendimiento de la pendiente de la recta tangente o sobre el análisis combinado de la curva con la constante de capacidad de atención de los sistemas sanitarios. Podríamos pensar en cómo es percibida la provisionalidad de las proyecciones matemáticas, que muchas veces son graficadas y que entran en conflicto con las recomendaciones epidemiológicas. Podríamos considerar cuáles son las posibilidades de discriminar entre los gráficos que representan datos empíricos y los que representan proyecciones. Pero lo que está claro y fuera de toda duda es que, para tomar postura ante las políticas y las acciones y revisar críticamente los discursos políticos y mediáticos, es absolutamente necesario poder encontrar el significado profundo de los gráficos. Es aquí donde la educación científica para la ciudadanía encuentra el desafío de trabajar sobre los sistemas semióticos que sostienen las ideas de la ciencia.

La enseñanza de los gráficos, como ya comentamos, se aborda en distintos espacios curriculares, entre los que se cuentan los cursos de matemática. Sin embargo, en estos cursos el uso de las representaciones y la direccionalidad de la enseñanza, que considera al gráfico el punto final de la instrucción no completa la necesaria aproximación a estos registros semióticos. De hecho, de no abordarse en las clases de ciencias, el procesamiento conceptual que requiere la resignificación de las representaciones a partir de la tensión con modelos de las disciplinas y datos de la experimentación no se alcanzaría. Es menester destacar que este tipo de procesamiento es el que tendría mayor valor en circunstancias como la coyuntura de la pandemia.

Durante la educación formal debe encararse una alfabetización gráfica o graphicacy (Postigo y Pozo, 2000), que sea complementaria a la alfabetización matemática y en la lengua natural, privilegiadas en todos los sistemas educativos. Esta alfabetización gráfica debería garantizar que los estudiantes hagan propias las reglas de los sistemas, reconozcan sus limitaciones y puedan construir y, sobre todo, interpretar gráficos. Sin embargo, creemos que se requiere más que un proceso de alfabetización con énfasis en las reglas de conformidad, tratamiento y conversión. Planteamos la perspectiva de llevar esta alfabetización gráfica a la dimensión de la educación representacional, que incluya, además de lo considerado con anterioridad, la enseñanza de los valores y funciones sociales de las representaciones, en particular las vinculadas a los modelos científicos. Así, la educación científica para la ciudadanía será tal en cuanto encare, también, la educación representacional fundamental para el desempeño pleno de derechos en las sociedades contemporáneas.

Esta reflexión que encaramos en tiempos de cambio pretende dejar la contemplación en pos de avanzar en dirección al rediseño de nuestras prácticas. La tarea no estaría completa sin considerar las posibles perspectivas para una educación científica para la ciudadanía que incluya a la educación representacional en la postpandemia, cuando la sociedad, los valores, la salud, el desarrollo de los pueblos y la educación no sean entendidos de la misma manera. Es más, estamos obligados a hacer el mayor esfuerzo para brindar insumos para ese rediseño que, junto con la capacidad creadora de la comunidad educativa, garanticen una mejor educación científica en los nuevos tiempos. Así, nuevamente comentaremos algunos productos propios, esta vez en el plano de la transferencia, que esperamos aporten pistas para esta reconstrucción.

La investigación que dio lugar a los estudios comentados en este trabajo se caracterizó por presentar una dimensión aplicada, permitiendo la generación de diferentes productos con potenciales usos en el contexto de la educación científica. Dentro de estos productos pueden diferenciarse: recomendaciones para la enseñanza, instrumentos metodológicos especialmente diseñados para el estudio de las representaciones gráficas, propuestas de formación docente y comunicaciones destinadas a profesores del área de distintos niveles educativos.

En primer lugar, surgen diferentes recomendaciones para la enseñanza de las ciencias naturales. Si bien estas no son directivas, pretenden servir como orientación para aquellos docentes que deseen incorporar la dimensión representacional a la reflexión sobre sus prácticas de enseñanza. Asimismo, se espera que estos lineamientos ayuden a promover, en el marco de los debates sostenidos sobre la educación científica para la ciudadanía en tiempos de pandemia, la discusión 
acerca de la compleja cuestión de la enseñanza y el aprendizaje con y sobre representaciones gráficas.

Un aspecto importante a considerar es el trabajo en el aula con las conceptualizaciones sobre los gráficos que operan en los estudiantes, a fin de que logren explicitarlas. Cobran particular interés aquellas ideas vinculadas a la caracterización de estas representaciones como herramientas cuya función principal sería ordenar y presentar información, empírica o teórica, y como constructos estrictamente escolares y/o científicos. Así, se podría trabajar con diversas situaciones problemáticas, vinculadas a la crisis sanitaria y a otras situaciones de interés social, en donde los gráficos fueran utilizados con otros fines, como la toma de decisiones o la predicción de fenómenos, en diversos ámbitos comunicativos cotidianos, como las redes sociales, y formales, como los discursos políticos. Esto tendería a favorecer la comprensión del carácter representacional, el reconocimiento de las potencialidades cognitivas de las representaciones gráficas y los fines y valores de las mismas en distintos ámbitos de la cultura.

Por otra parte, los estudiantes necesitan encontrar oportunidades en clase para aprender y afianzar habilidades y estrategias que les permitan realizar tareas de alta demanda cognitiva con representaciones. Estas actividades, en términos vigotskianos, deben encontrarse dentro de la zona de desarrollo próximo, por lo que, para plantearlas, el profesor debe conocer a qué nivel de procesamiento de la información gráfica acceden sus alumnos. Es decir, es necesario llevar adelante una evaluación formativa que permita evidenciar el nivel de aprehensión por parte de los estudiantes de todo aquello vinculado con las representaciones. A tal fin, se pueden proponer diferentes situaciones en las que los alumnos deban identificar y diferenciar entre los distintos niveles de información y la relación entre ellos. Además, se torna necesario tomar en cuenta algunos aspectos propuestos en nuestros estudios que se encuentran íntimamente relacionados al procesamiento a nivel de la información conceptual, tales como las referencias a modelos propios de las ciencias naturales mediante el uso de múltiples sistemas de representaciones y la realización de actividades ligadas a la semiosis, especialmente el tratamiento y la conversión.

La evaluación formativa a la que hacemos referencia brindaría información valiosa para realizar una vigilancia representacional que adecue las actividades a las necesidades y posibilidades de los estudiantes (Idoyaga y Lorenzo, 2019). Esta vigilancia debe incluir también otros aspectos como los vinculados a la identidad de las representaciones desplegadas en la enseñanza con las que sostienen los modelos científicos que se enseñan y los fines y valores de estas representaciones en la ciencia y en las cuestiones de corte socio científicos. Es precisamente esa vigilancia, entendida como la búsqueda sistemática de evidencia durante el proceso de enseñanza, la que garantizará una adecuada educación representacional que dote a la ciudadanía de las herramientas para poder validar y criticar los discursos que las incluyan.

Otra cuestión que se desprende de nuestros resultados y que cobra especial relevancia en este contexto es que la posibilidad de acceder al procesamiento conceptual se encuentra fuertemente condicionada por el contenido de la representación. Es decir, el tipo de procesamiento dependerá de aquello representado. Por ende, es necesario que el profesor realice una vigilancia representacional reconociendo la imposibilidad de disociar representación de contenidos e identificando aquellas representaciones que por sus referentes requieran de una mayor demanda cognitiva que otras de idéntica estructura gráfica. En este sentido, los gráficos asociados a la pandemia por COVID-19 resultan de alta complejidad, ya que dentro de una misma representación se combinan modelos teóricos provenientes de diversos campos disciplinares, tales como la demografía (tasa de mortalidad), la infectología (tasa de contagio) y la salud pública (capacidad de atención sanitaria).

Los instrumentos generados a lo largo de las investigaciones comentadas encierran en sí mismos la potencialidad de ser útiles, una vez realizadas las adaptaciones necesarias, no sólo para otros investigadores, sino, en algunos casos y con la orientación adecuada, para profesores de ciencias naturales en ejercicio en distintos niveles del sistema educativo. De este modo, la adecuación de estos instrumentos podría facilitar la vigilancia representacional sugerida en los párrafos anteriores, pudiendo los profesores reconocer la naturaleza, los usos y la cantidad de información de las representaciones que aparecen en los materiales didácticos que utilizan, identificando posibles encapsulamientos representacionales y otros sesgos, así como explicitar algunas conceptualizaciones e identificar el nivel de procesamiento de gráficos a los que acceden sus alumnos.

Para finalizar, y a modo de corolario, la mayor perspectiva y clave para el debate que abre esta reflexión se encuentra en la definición política de representación. En términos sencillos, actuar en nombre de otros. La ciudadanía requiere la comprensión plena de quienes los representan y, abusando del juego de palabras, esto requiere entender las representaciones que los representantes usan para validar sus acciones en el tiempo que dura su representación. 


\section{Referencias bibliográficas}

Adúriz-Bravo, A. (2020). Contributions to the Nature of Science: Scientific Investigation as Inquiry, Modeling, and Argumentation. En C. N. El-Hani, M. Pietrocola, E. Mortimer y M. R. Otero, Science Education Research in Latin America (pp. 394-425). Estados Unidos: Brill Sense.

Ainley, J., Nadi, H., \& Pratt, D., (2000). The construction of meaning for trend in active graphing. International Journal of Computers for Mathematical Learning, 5, 85 - 114.

Álvarez Tamayo, O.(2011). Incidencia de las representaciones múltiples en la formación del concepto Transporte celular en estudiantes universitarios. (Tesis inédita de Maestría). Universidad de Manizales, Colombia.

Arias, C., Leal, L., \& Organista, M., (2011). La modelación de la variación, un análisis del uso de las gráficas cartesianas en los libros de texto de biología, física y química de secundaria. Revista de Ciencias, 15, 93-128.

Barnett, J., \& Hodson, D., 2001). Pedagogical context knowledge: Toward a fuller understanding of what good science teachers know. Science Education, 85(4), 426453.

Chamizo, J. (2010). Una tipología de los modelos para la enseñanza de las ciencias. Revista Eureka sobre Enseñanza y Divulgación de las Ciencias, 7(1), 26-41.

Cox, R., (1999). Representation construction, externalised cognition and individual differences. Learning and Instruction, 9(4), 343-363. doi: 10.1016/S09594752(98)00051-6

de Miguel, R., (2020).Polémica en el Reino Unido por la estrategia contra el virus: un contagio controlado. El país. Disponible en: https://elpais.com/oiead/2020-03-13/ la-estrategia-del-gobierno-de-johnson-contra-elcoronavirus-divide-a-la-comunidad-cientifica.html.

Duval, R. (2017). Understanding the mathematical way of thinking. Springer, Cham.

Duval, R., (1999). Semiosis y pensamiento humano. Registros semióticos y aprendizajes intelectuales. Cali, Colombia: Universidad del Valle y Peter Lang S.A.

Eysenck, M. W., \& Keane, M. T., (1990). Cognitive psychology: A student's handbook. Estados Unidos: Lawrence Erlbaum Associates.

Farré, A. S., Idoyaga, I., \& Lorenzo, M. G., (2014). Documentación del conocimiento didáctico en uso en clases universitarias de química orgánica y física. En M. G. Lorenzo, S. Daza y A. Garritz, (Eds.). Conocimiento Didáctico del Contenido. Una perspectiva Iberoamericana (pp. 296-337). Saarbrücken, Alemania: Académica Española.

Font, V., Acevedo, J., Castells, M. \& Bolite J. (2008). Metáforas y ontosemiótica. El caso de la representación gráfica de funciones en el discurso escolar. En P. Lestón (Ed.)
Acta Latinoamericana de Matemática Educativa, (pp. 667-676). México: Colegio Mexicano de Matemática Educativa A.C. y Comité Latinoamericano de Matemática Educativa A.C.

Galagovsky, L., Di Giacomo, M. A., \& Castelo, V., (2009). Modelos vs. dibujos: el caso de la enseñanza de las fuerzas intermoleculares. Revista electrónica de Enseñanza de las Ciencias, 8(1), 1-22. Recuperado de http://reec.uvigo.es/volumenes/volumen8/ART1 Vol8 N1.pdf.

García García, J. J., (2005). La comprensión de las representaciones gráficas cartesianas presentes en los libros de texto de ciencias experimentales, sus características y el uso que se hace de ellas en el aula (Tesis inédita de doctorado). Universidad de Granada, Granada, España.

García García, J. J., \& Perales, F., (2006). ¿Cómo usan los profesores de química las representaciones semióticas? Revista Electrónica de Enseñanza de las Ciencias, 5(2), 247-259. Recuperado de http://reec.uvigo.es/ volumenes/volumen5/ART3 Vol5 N2.pdf.

Idoyaga, I. \& Lorenzo, M. G. (2019). Las representaciones gráficas en la enseñanza y el aprendizaje de la física en la universidad (Tesis inédita de doctorado). Universidad de Buenos Aires, Argentina.

Idoyaga, I., Maeyoshimoto, J., Moya, C. N. \& Granchetti, H., (2017). Uso y cantidad de información de gráficos en materiales didácticos de Física. Enseñanza de las ciencias, (Extra), 1821-1826.

Idoyaga, I., \& Lorenzo, M. G., (2013). Los gráficos. Conceptualizaciones, creencias y concepciones en educación superior. Enseñanza de las Ciencias, (Extra), 1771-1777.

Idoyaga, I., \& Lorenzo, M. G., (2016). La compleja apropiación de la información conceptual de los gráficos cartesianos en las aulas de física en la universidad. Revista de Enseñanza de la Física, 28(Extra), 279-286.

Idoyaga, I., \& Lorenzo, M. G., (2018). Las representaciones gráficas en la enseñanza y en el aprendizaje de la física en la universidad. En M. G. Lorenzo, A. Ortolani,y H. S. Odetti (Comps.) Comunicando la Ciencia. Avances en Investigación en Didáctica de la Ciencia (pp. 173-179). Santa Fe, Argentina: UNL.

Jiménez-Tejada, M. P., Sánchez-Monsalve, C., \& GonzálezGarcía, F. (2013). How Spanish primary school students interpret the concepts of population and species. Journal of Biological Education, 47(4), 232-239.

Leinhardt, G., Zalavsky, O., \& Stein, M. K., (1999). Functions, Graphs and graphing. Task a Learning and teaching. Review of Educational Research, 60(1), 1-64.

Lemke, J. L., (1993). Discourse, dynamics, and social change. Cultural dynamics, 6 (1-2), 243-275. 
Lemke, J. L., (1997). Aprender a hablar ciencia: Lenguaje, Aprendizaje y Valores. México: Paidós.

Lemke, J. L., (1998). Multiplying meaning: visual and verbal semiotics in scientific text. En J. R. Martin y R. Veel, (Eds.), Reading science: critical and functional perspectives of discourses of science (pp. 87-111). New York, Estados Unidos: Routledge.

Lemke, J. L., (2002). Enseñar todos los lenguajes de la ciencia: palabras, símbolos, imágenes y acciones. En M. Benlloch (comp.), La educación en ciencias: Ideas para mejorar su práctica (159-186). Barcelona, España: Paidós.

Lieben, L. S., \& Downs, R.M., (1992). Developing an understanding of graphic representations in children and adults: the case of GEO-graphics. Cognitive Development, 7(3), 331-349.

Lombardi, G., Caballero, C., \& Moreira, M. A., (2009). El concepto de representación externa como base teórica para generar estrategias que promuevan la lectura significativa del lenguaje científico. Revista de Investigación, 33(66), 147-186.

López-Manjón, A., \& Postigo, Y., (2016) ¿Qué libro de texto elegir? La competencia visual en las actividades con imágenes. Revista Eureka sobre Enseñanza y Divulgación de las Ciencias, 13(1), 84-101.

Lorenzo, M. G., Farré, A. S., \& Rossi, A. M., (2018). La formación del profesorado universitario de ciencias. El conocimiento didáctico y la investigación científica. Revista Eureka sobre Enseñanza y Divulgación de las Ciencias, 15(3), 301-316.

Lorenzo, M. G., \& Pozo, J. I., (2010).La representación gráfica de la estructura espacial de las moléculas: eligiendo entre múltiples sistemas de notación. Cultura y Educación, 22(2), 231-246.

Macedo, B. (2016). Educación científica. Montevideo: UNESCO.

Márquez, C., \& Prat, A., (2005). Leer en clase de Ciencias. Enseñanza de las Ciencias, 23(3), 431-440.

Martí, E., (2003). Representar el mundo externamente. La adquisición infantil de los sistemas externos de representación. Madrid, España: Antonio Machado

Martín-Páez, T., Aguilera, D., Perales-Palacios, F. J., \& VílchezGonzález, J. M. (2019). What are we talking about when we talk about STEM education? A review of literature. Science Education, 103(4), 799-822.

Matus, L., Benarroch, A., \& Nappa, N., (2011). La modelización del enlace químico en libros de texto de distintos niveles educativos. Revista Electrónica de Enseñanza de las Ciencias, 10(1), 178 - 201. Recuperado de http://reec. uvigo.es/volumenes/volumen10/ART9 Vol10 N1.pdf.

Núñez, F., Banet Hernández, E., \& Cordón Aranda, R., (2009). Capacidades del alumnado de educación secundaria obligatoria para la elaboración e interpretación de gráficas. Enseñanza de las ciencias, 27(3), 447-462.

Otero, M.R. (2004). Investigación en imágenes en la educación en ciencias. Imágenes, palabras y conversaciones. Atas IV Encontro Nacional De Pesquisa Em Educação Em Ciências. Brasil: ABRAPEC. Recuperado de http://fep. if.usp.br/ profis/arquivos/ivenpec/Arquivos/Conf/ OTERO.pdf.

Perales, F., \& Jiménez, J., (2002). Las ilustraciones en la enseñanza-aprendizaje de las ciencias. Análisis de libros de texto. Enseñanza de las ciencias, 20(3), 369-386.

Pérez-Echeverría, M. P., Martí, E., y Pozo, J. I., (2010). Los sistemas externos de representación como herramientas de la mente. Cultura y Educación, 22(2), 133-147.

Postigo, Y., \& Pozo, J. I., (2000). Cuando una gráfica vale más que 1000 datos: la interpretación de gráficas por alumnos adolescentes. Infancia y Aprendizaje, 90, 89100.

Pozo, J. I., (2001). Humana mente. El mundo, la conciencia y la carne. Madrid, España: Morata.

Pozo, J. I., (2017). Aprender más allá del cuerpo: de las representaciones encarnadas a la explicitación mediada por representaciones externas. Infancia y Aprendizaje: Journal for the Study of Education and Development, 40(2), 219-276.

Pozo, J. I., \& Flores, F. (Coords.) (2015). Cambio conceptual y representacional en el aprendizaje y la enseñanza de la ciencia. Madrid, España: Antonio Machado.

Pozo, J. I., \& Postigo, Y., (1999). Hacia una nueva alfabetización: El aprendizaje de información gráfica. En Pozo, J. I. y Monereo, C., (Coords.), El aprendizaje estratégico (pp. 251-270). Madrid: Aula XXI. Santillana.

Roth, W. M., Bowen, G. M., y McGinn, M. K., (1999). Differences in graph-related practices between high school biology textbooks and scientific ecology journals. Journal of Research in Science Teaching, 36(9), 9771019.

Roth, W. M., \& McGinn, M. K., (1997). Graphing: cognitive ability or practice. Science Education, 81(1), 91-106.

Schnotz, W., \& Bannert, M., (2003). Construction and interference in learning from multiple representation. Learning and Instruction, 13(2), 141-156.

Shah, P., Freedman, E. G., \& Vekiri, I., (2005). The comprehension of quantitative information in graphical displays. En P. Shah y A. Miyake, (Eds.), The Cambridge handbook of visuospatial thinking (pp.426-476). Estados Unidos, Cambridge University Press.

Shah, P., \& Hoeffner, J., (2002). Review of graph comprehension research: Implications for instruction. Educational psychology review, 14(1), 47-69. 
Shulman, L. (1987). Knowledge and Teaching: Foundations of a new reform. Harvard Educational Review, 57(1), 21-33.

Shulman, L. S. (1986). Those who understand: knowledge growth in teaching. Educational Researcher, 15(2), 4-14.

Solar, H., Deulofeu, J. \& Azcárate, C. (2015). Competencia de modelización en interpretación de gráficas funcionales. Enseñanza de las Ciencias, 33(2), 191-210.

Suárez, L., \& Cordero, F., (2008). Elementos teóricos para estudiar el uso de las gráficas en la modelación del cambio y de la variación en un ambiente tecnológico. Revista Electrónica de Investigación en Educación en Ciencias, 3(1), 51-58.
Treagust, D. F., (2018). The Importance of Multiple Representations for Teaching and Learning Science (pp. 215-233). En M. Shelley y S. Kiray (Eds.), Education Research Highlights in Mathematics, Science and Technology 2018. Estados Unidos: ISRES. 